Dado que el brunca es una lengua muy desplazada y prácticamente sin hablantes con alta o media competencia productiva, ya no resulta posible documentar discurso ni -al decir de Quesada Pacheco- esclarecer con ellos dudas acerca de determinadas estructuras gramaticales, razón por la cual la publicación de esta Gramática se torna aún más relevante: se trata de la sistematización de un corpus cerrado que sin duda ha de resultar invaluable para los esfuerzos de enseñanza y revitalización de la lengua.

Carlos Sánchez Avendaño

Universidad de Costa Rica

San José, Costa Rica

\title{
Ana María Díaz-Marcos (Ed.). Escenarios de crisis. Dramaturgas españolas en el nuevo milenio. Sevilla: Benilde Ediciones, 2018, 531 páginas
}

Escenarios de crisis. Dramaturgas españolas en el nuevo milenio viene a gritar y bien fuerte, si bien no es la primera vez que esto se hace, que a los estudios teatrales les amenaza la "invisibilidad y olvido" (17) en cuanto a la obra de autoría femenina se refiere. Se advierte ya desde sus primeras líneas el "desapego" con el que la crítica al uso ha tratado a buena parte de las dramaturgas españolas. Se explicita, igualmente, la intención de reivindicar un hueco y arrojar luz, desde una perspectiva diacrónica acotada a las últimas décadas, sobre la escena dirigida y representada por mujeres: "lúcida prefiguración del ambiente en el que producen las autoras teatrales en este nuevo milenio" (18).

Este magnífico volumen antológico acoge y pone en escena una "dramaturgia de la búsqueda" (19) a partir de la difusión de quince piezas teatrales (once de ellas inéditas cuando esta edición ve la luz) de autoría exclusivamente femenina.

Se trata de una edición a cargo de la profesora titular de Literatura española Ana María Díaz-Marcos (Department of Literatures, Cultures \& Languages, Universidad de Connecticut) que incorpora, junto a los textos teatrales (desde la página 119 a la 521), un revelador estudio introductorio estructurado en varios epígrafes (17-118), y un epílogo, obra de la profesora Ruth Z. Yuste-Alonso (523-531).

En palabras de la antóloga, el volumen "aspira a documentar itinerarios y respuestas teatrales a las crisis globales del nuevo milenio de modo que se hace necesario evaluar en qué situación se encuentra la autoría femenina en el terreno de las artes y la práctica teatral en las últimas dos décadas" (18).

En efecto, a modo de auténtico estado de la cuestión, esta obra de un total de 531 páginas y nacida como producto digital descargable junto a una tirada en papel, no venal, de 150 ejemplares, transita y hasta invade espacios antes vetados a la autoría femenina al destacar y ponderar la mirada de la mujer artista. Y ello se infiere por los objetivos que identificamos en su estudio introductorio: primeramente, se pretende alejar a la mujer (como productora, autora, teatrista y también como actriz) de la posición periférica y secundaria que tradicionalmente ha ocupado en el mundo de la escena, trasunto de la vida misma. En segundo lugar, el texto en su conjunto se propone como revulsivo para la crítica al uso y, desde la contundencia de su discurso (no en vano su antóloga habla de activismo dramático), intenta sacudir consciencias y "modificar la trayectoria de una historiografía teatral que ha prestado poca atención a las dramaturgas y sus obras" (33). Finalmente, este conjunto de textos, quizá sin pretenderlo 
a priori, conforma un nuevo corpus de piezas (¿nuevo canon quizá?) susceptible de captar también el interés del espacio docente. Esta prospectiva didáctica se garantiza por su propia distribución digital, por su naturaleza contemporánea (autoras vivas), por su carácter inclusivo, así como por la vitalidad de sus temas, por su potencial como trasunto de la lengua y cultura española y, cómo no, por hacer un guiño significativo a otros códigos comunicativos y estéticos como el cine, la radio, la canción o internet.

Desde sus primeras líneas, su editora nos involucra en una reflexión sobre la mujer y el oficio del drama que arranca con el contraste de la propia portada: una acuarela que muestra una escenografía, desconocida como su autora, Victorina Durán y Cebrián, sin eco (una de las sinsombrero del '27) pese a una sólida formación y trayectoria teatral en Madrid y Buenos Aires.

Articula la profesora Díaz-Marcos su estudio introductorio en cinco distintos epígrafes de autoría propia (17-89): "Visibilizar a las dramaturgas españolas"; "Contemporáneas: escenarios de crisis"; "Teatro para leer: propuestas para un ágora/aula digital"; "Teatro contemporáneo y mundialización”; “Teatro, violencia, poder y marginación”. No refieren dichos epígrafes compartimentos estancos: simplemente subrayan el aspecto sobre el que se desea reflexionar. Coronan esta introducción las apostillas de las propias autoras a su concepto y visión del teatro (90-96), unas notas (97-102) y las referencias bibliográficas (103-118).

Como ya se advierte desde el enunciado descriptivo de estos cinco epígrafes, asistimos, decíamos igualmente en nuestras primeras líneas, a una suerte de estado de la cuestión. Se desgrana aquí, en un acertado continuum, la necesidad de reivindicar que el escenario teatral también es femenino desde su empoderamiento real y protagónico; se constata la recuperación de una nómina activa y altamente productiva de creadoras teatrales; se señalan las oportunidades de la contribución de la lectura teatral al escenario sociocultural y educativo; se reconoce, asimismo, la relevancia de la perspectiva actual (a la vez local y a la vez universal) de las obras aquí recogidas y, finalmente, se identifica el énfasis en un territorio común, verdadero telón de fondo de las piezas: la asunción del teatro como revulsivo agente de cambio, el teatro como sanación, como negociación y respuesta a la crisis que no es sino la vida misma (teatro humanista, "vida trepando por la vida", 93). Esta más que elocuente metáfora, debida a una de las autoras (Yolanda García Serrano), nos invita a detenernos ahora especialmente en la oportuna inclusión que la profesora Díaz-Marcos hace de un breve apartado que recoge la propia voz de las creadoras.

Bajo el epígrafe "Respuestas dramáticas a la crisis" (90-96) cada una de las autoras desvela su sentir ante la pregunta: “¿Cuál es el valor que otorgáis al teatro, la escena, la vivencia y/o el quehacer teatral en la presente coyuntura de crisis global?". Ello nos parece de gran acierto pues nos permite no solo entender mejor cada una de las quince piezas que conforman la antología, sino participar, solidariamente, de un mismo manifiesto: el teatro como "lugar de resistencia" (Lola Blasco, 90), "medio ideal para compartir" (Marta Buchaca, 90), "ritual [...] que nos hace más humanos" (Antonia Bueno Mingallón, 91), "microcosmos [...] para reflexionar sobre los problemas y las inquietudes de la actualidad" (Diana de Paco, 91), "consecuencia de la evolución que denominamos vida" (Juana Escabias, 92), "un ejercicio matriz de rescate que hay que asumir" (Tina Escaja, 92), "trascender" (Beth Escudé i Gallès, 93), "manera de reivindicar una mirada" (Verónica Fernández, 93), "la vida y el teatro [...] entrelazados como una enredadera trepando por el tronco de un árbol" (Yolanda García Serrano, 93), "un tsunami de vivencia" (Eva Guillamón, 94), "formas de resistencia frente a la ideología dominante" (Gracia Morales, 94), "una oportunidad para propiciar un cambio" (Carmen Pombero, 95), 
"seguirá existiendo e intentando mover cauces" (Carmen Resino, 95), “capaz de meter el dedo en la llaga como nadie" (Laila Ripoll, 95), "espacio asambleario" (Laura Rubio Galletero, 96).

Se cierra el estudio introductorio con las oportunas notas y las referencias bibliográficas. Organiza así la profesora Díaz-Marcos su texto con este cierre que le permite (desde esta perspectiva dialógica) aportar más respuestas y fundamentar adecuadamente las reflexiones que nutren su estudio.

El cuerpo central del volumen lo ocupan las quince obras teatrales seleccionadas (119521). Sus autoras pertenecen a varias generaciones de dramaturgas (sus fechas de nacimiento oscilan entre 1941 y 1983). Las une, sin embargo, "la firme convicción del poder del teatro para educar, iluminar, plantear interrogantes y reflexiones, presentando a la sociedad ante un espejo que la humaniza" (31). Precede a cada pieza una breve bio-bibliografía de las autoras que nos permite ubicar sus respectivas trayectorias: todas ellas a caballo entre la actividad teatral (como dramaturgas, directoras de escena, guionistas o intépretes), la docencia e investigación y otros ámbitos artísticos y creativos como la fotografía, la producción audiovisual, el cine o la música.

Los títulos, sus autoras y algunas circunstancias de las piezas aquí reunidas son las siguientes: La Confesión de Don Quijote, de Lola Blasco; Kramig, de Marta Buchaca; Las Mil y una Muertes de Sarah Bernhardt, de Antonia Bueno Mingallón (obra beneficiada de una ayuda económica de la Generalitat Valenciana, en 2005); Apofis, de Diana de Paco; No Le Cuentes a Mi Marido que Sueño con Otro Hombre... Cualquiera, de Juana Escabias (publicada anteriormente en el año 2015); Madres. Drama Urbano en Cuatro Partes, de Tina Escaja (pseudónimo Alm@ Pérez), pieza publicada anteriormente en el año 2007 y también representada en el estado de Vermont, EE. UU.; La Gallinita Ciega, de Beth Escudé i Gallès; Liturgia de un Asesinato, de Verónica Fernández Rodríguez (cuenta con varias representaciones en el año 2014); Entrevista Atravesada, de Yolanda García Serrano; Si en la Ciudad la Luz, de Eva Guillamón (pieza becada por la Comunidad de Madrid en el año 2009); Cortinas Opacas, de Gracia Morales; Madres de Cristal, de Carmen Pombero; La Otra Boda, de Carmen Resino (traducida al catalán y estrenada en 2016); Disparate Último (Lux Ex Tenebris), de Laila Ripoll; finalmente, Lady Day, de Laura Rubio Galletero.

Estas quince piezas seleccionadas para esta antología no obedecen, advierte su editora, a un criterio temático preestablecido, pero sí comparten su potencial como obras inspiradoras, referentes de situaciones, temas y conflictos que aseguran y salvaguardan el interés por verlas $\mathrm{y}$, en el caso que nos ocupa, leerlas.

Concluye el volumen con el epílogo "Miradas entre bastidores: reflexiones sobre autoría femenina en escenarios de crisis" (523-531), de la mano de la profesora Yuste-Alonso. Su aportación se acompaña de notas y de referencias bibliográficas y entre otras observaciones ofrece una personal revisión del concepto de autor del semiólogo Roland Barthes. La profesora reivindica la consideración de una autoría "heteróclita, polifónica, fluida, capaz de albergar a todo tipo de autores independientemente de su sexo, raza o clase" (525).

Podemos considerar que este volumen tiene, entre sus destinatarios inmediatos, no solo a la comunidad teatral, sino también al ámbito académico y educativo y, en general, a quienes sienten interés, pero también pasión por el teatro que es, más que oficio, arte y vida, en la misma línea reivindicativa del Lorca más social y combativo. No en vano, la profesora Ana María Díaz-Marcos subraya en este volumen la perentoria necesidad de una perspectiva crítica; y su obra es por ello un tour de force (89), un grito que defiende la acción "civilizadora" (61) del teatro en unas páginas que la autora tardó tres años en preparar y ofrecer generosamente 
en esta edición en abierto. Ojalá el grito se torne esperanzador y augure un cambio: que la obra teatral femenina salga también por la misma puerta grande que la masculina; la frase de Antonia Bueno que la antóloga escoge para el cierre del volumen, con la cual rompe el blanco de la hoja de respeto o cortesía, así lo hace presagiar: "El futuro del teatro no es claudicación, sino apertura a riquísimas oportunidades".

Juana-Rosa Suárez Robaina Universidad de Las Palmas de Gran Canaria Las Palmas, España 